\title{
A rare case of congenital anomalous/aberrant systemic artery to pulmonary venous fistula in a 4-month-old child with co-existent mitral valve prolapse and mitral regurgitation
}

\author{
Ranjana Jayan, ${ }^{1}$ Koteshwara Prakashini, ${ }^{2}$ Ranjan K Shetty, ${ }^{3}$ \\ Ravikanti Krishna Chaitanya ${ }^{3}$
}

${ }^{1}$ Department of

Radiodiagnosis, Kasturba Medical College Manipal, Manipal, Karnataka, India ${ }^{2}$ Department of Radiology and Imaging, Kasturba Medical College Manipal, Manipal, Karnataka, India

${ }^{3}$ Department of Cardiology, Kasturba Medical College

Manipal, Manipal, Karnataka, India

\section{Correspondence to} Dr Koteshwara Prakashini, docprakashinik@yahoo.co.in

Accepted 2 September 2015 CrossMark

\section{To cite: Jayan $\mathrm{R}_{\text {, }}$} Prakashini K, Shetty RK, et al. BMJ Case Rep Published online: [please include Day Month Year] doi:10.1136/bcr-2015210865

\section{DESCRIPTION}

We present a rare case of descending aorta pulmonary venous fistula (DAPVF) in a 4-month-old child with mitral valve prolapse who was being evaluated for failure to thrive. Echocardiogram revealed abnormal turbulence in the left atrial appendage and mitral valve prolapse with mitral regurgitation (to a mild degree). Low dose non-ECG-gated cardiac CT (two postcontrast phases) and CT of the thorax $(80 \mathrm{kVp}, 50 \mathrm{mAs}$ with automated tube current modulation) were performed using a Philips Brilliance 64-slice MDCT machine. An abnormal dilated artery arising from the descending

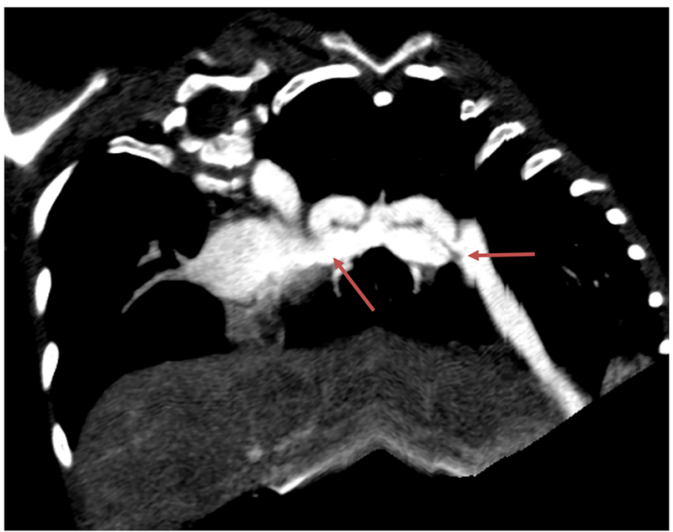

Figure 1 Curved multiplanar reformatted CT image showing abnormal vessel connecting descending thoracic aorta and left inferior pulmonary vein (arrows). thoracic aorta at the D7-D8 level on the left, giving rise to a nidus of tortuous vessels in the superior segment of the left lower lobe (figures 1-4) and draining into the left inferior pulmonary vein resulting in a left to left shunt was noted (figure 5).

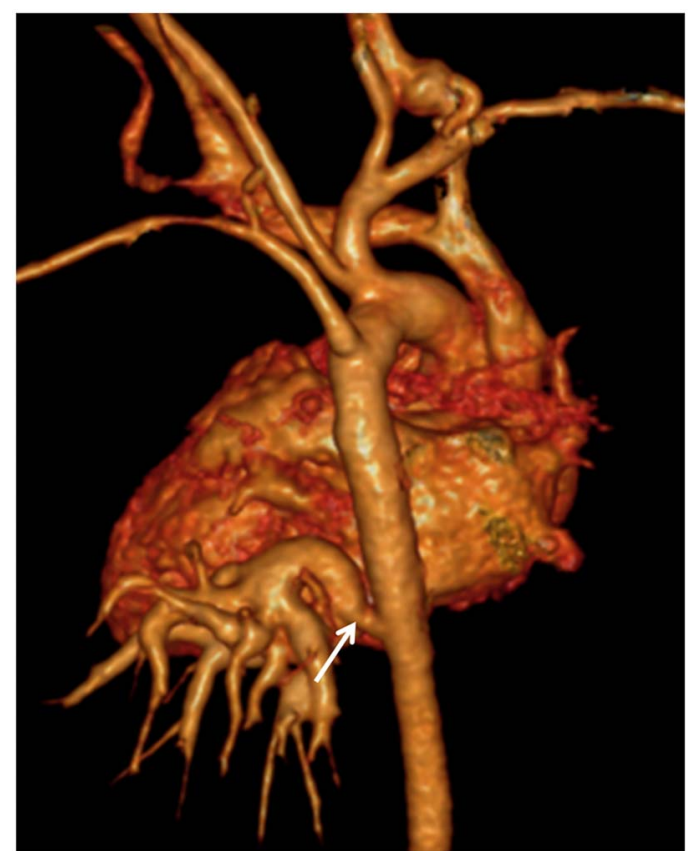

Figure 2 Three-dimensional reformatted CT image showing origin of the abnormal vessel from descending thoracic aorta (arrow) and nidus.

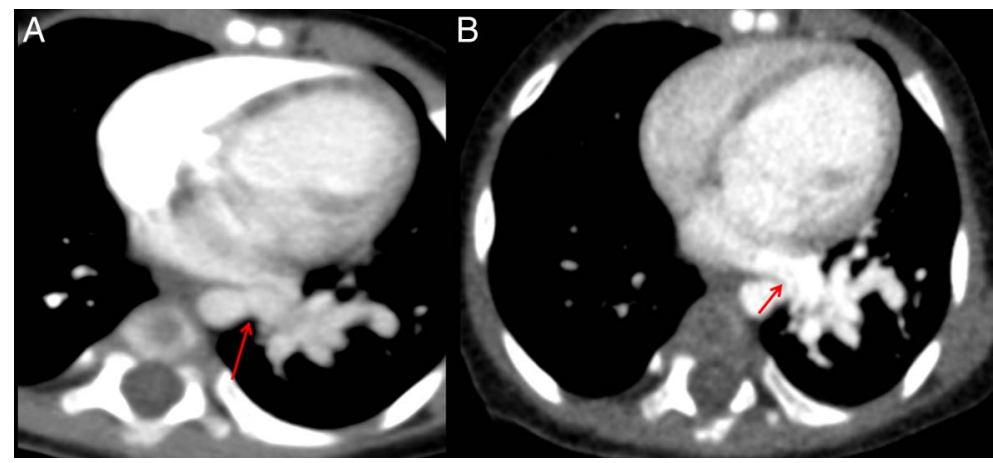

Figure 3 (A) Axial CT image in pulmonary arterial phase showing absence of significant contrast filling within the abnormal vessel and nidus (arrow); and (B) axial CT image at $30 \mathrm{~s}$ post-contrast injection showing contrast opacification of abnormal vessel (arrow) and nidus, which is equivalent to that of descending thoracic aorta. 


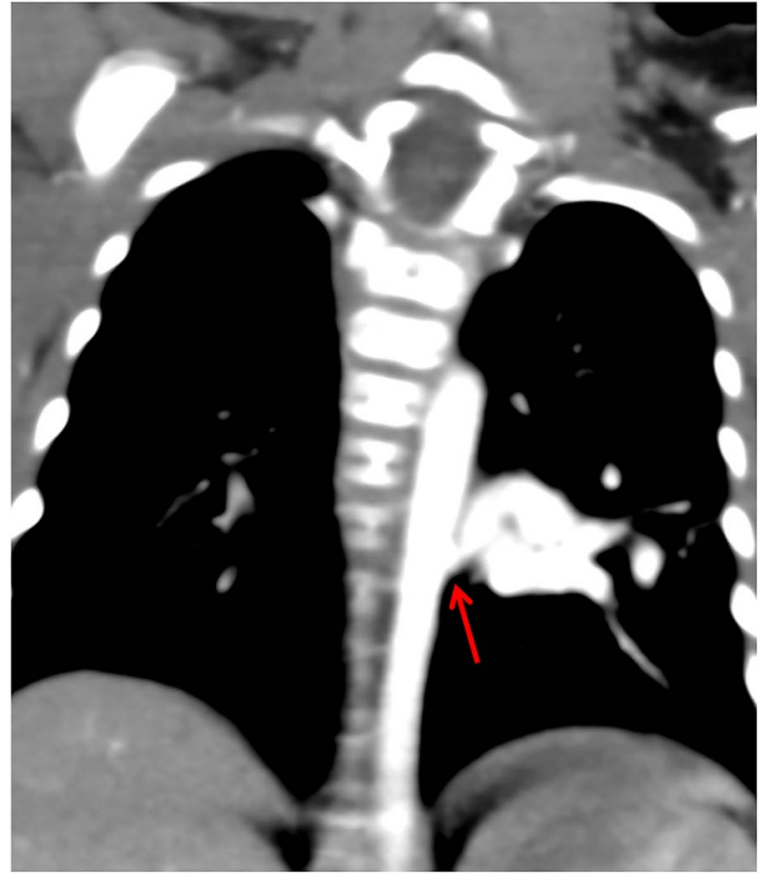

Figure 4 Coronal post-contrast CT image in arterial phase showing contrast opacification of abnormal vessel (arrow) and nidus, which is equivalent to that of descending thoracic aorta.

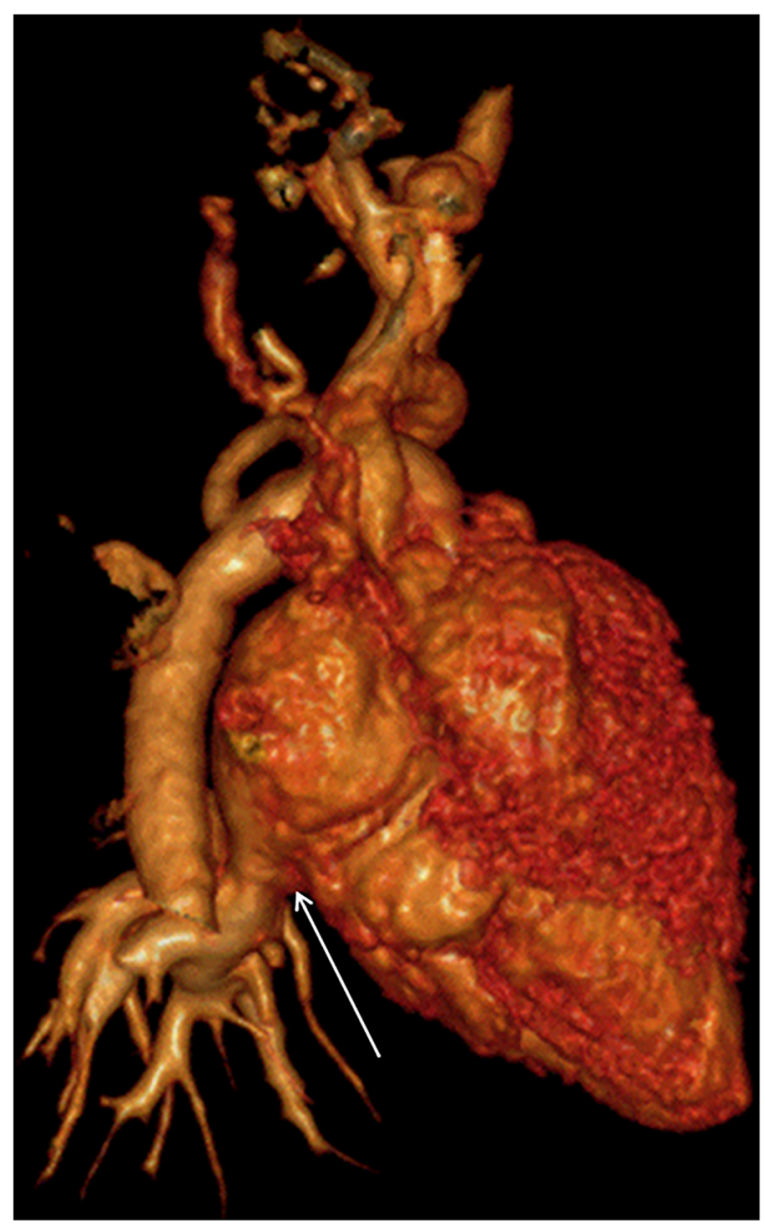

Figure 5 Three-dimensional reformatted CT image showing communication of the abnormal vessel with left inferior pulmonary vein (arrow) and nidus.
Left ventricular enlargement and mild plethora in the left lower lobe were seen, with no pulmonary vein dilation. Pulmonary arterial circulation and bronchial tree were normal with no sequestration. Surgical management was planned for a later age. To the best of our knowledge, no other similar case with a concomitant valvular heart disease has been reported in the English literature. Cardiac CT is helpful when echocardiography fails to identify the cause of abnormal pressure variation in cardiac chambers. Cardiac CT can also diagnose the presence of lung sequestration, ${ }^{1}$ which decides subsequent disease management. ${ }^{2}$ Systemic branches from the aorta supply the primitive lung and are replaced by the pulmonary arteries (from the 6th aortic arch) around the fifth week, failure of which (due to pulmonary oligaemia) is proposed as the theory for pulmonary arterialisation (pseudosequestration). ${ }^{3}$

\section{Learning points}

- Descending aorta pulmonary venous fistula (DAPVF) is a rare congenital anomaly that has to be ruled out by tomographic investigations whenever there is abnormal pressure variation or turbulence in the left atrium/pulmonary veins.

- Pulmonary sequestration is a condition in which the lung parenchyma is supplied by the anomalous systemic artery whereas DAPVF is a left to left shunt with no involvement of lung parenchyma.

- The importance of tomographic investigations in differentiating these two entities lies in the fact that DAPVF is surgically curable with ligation of the abnormal artery whereas in pulmonary sequestration, ligation of the artery causes lung infarction. Treatment of sequestration is resection of the abnormal lung parenchyma.

Competing interests None declared.

Patient consent Obtained.

Provenance and peer review Not commissioned; externally peer reviewed.

\section{REFERENCES}

1 Dahiya A, Collier $P$, Krasuski $R$, et al. Aorta-to-pulmonary vein fistula in an asymptomatic 25-year-old man. Circulation 2013;127:1727-9.

2 Jariwala P, Ramesh G, Sarat Chandra K. Congenital anomalous/aberrant systemic artery to pulmonary venous fistula: closure with vascular plugs \& coil embolization. Indian Heart J 2014;66:95-103.

3 Yamanaka A, Hirai T, Fujimoto $T$, et al. Anomalous systemic arterial supply to normal basal segments of the left lower lobe. Ann Thorac Surg 1999;68:332-8. 
Copyright 2015 BMJ Publishing Group. All rights reserved. For permission to reuse any of this content visit http://group.bmj.com/group/rights-licensing/permissions.

BMJ Case Report Fellows may re-use this article for personal use and teaching without any further permission.

Become a Fellow of BMJ Case Reports today and you can:

- Submit as many cases as you like

- Enjoy fast sympathetic peer review and rapid publication of accepted articles

- Access all the published articles

- Re-use any of the published material for personal use and teaching without further permission

For information on Institutional Fellowships contact consortiasales@bmjgroup.com

Visit casereports.bmj.com for more articles like this and to become a Fellow 